\title{
Chapter 4 \\ The Domestication of Misoprostol for Abortion in Burkina Faso: Interactions Between Caregivers, Drug Vendors and Women
}

\author{
Seydou Drabo
}

\section{Introduction}

Misoprostol has been hailed as a revolution for maternal health globally because of its potential to reduce mortality and morbidity from post-partum haemorrhage and unsafe abortion (Potts, 2006), providing relatively safe and discreet termination of pregnancy (Winikoff \& Sheldon, 2012). Since 2005, the World Health Organization (WHO) has recognized misoprostol as a lifesaving drug and recommended that it be included on the list of essential medicines, although only 'where permitted under national law and culturally acceptable' (World Health Organization, 2006). Advocates of safe abortion services, however, fought for its inclusion in the treatment of post-partum haemorrhage in countries with restrictive abortion laws, with the expectation that once it is in the health system, women will be able to access it and thereby avoid harmful abortion procedures (Fernandez et al., 2009; Hofmeyr, 2012).

A recent report examining the safety of abortion globally suggests that clandestine abortion in legally restrictive settings is becoming relatively safer as misoprostol replaces harmful methods (Singh et al., 2018). However, we know little about how women actually use misoprostol to induce abortion. This chapter addresses this knowledge gap by examining how misoprostol is acquired and used by women, drug vendors and healthcare workers to manage unwanted pregnancy in Ouagadougou, the capital of Burkina Faso in West Africa. Previous studies have shown that privileged individuals are able to circumvent Burkina Faso's restrictive abortion law by resorting to private clinics that offer clandestine abortions (Storeng \& Ouattara, 2014). Misoprostol is marketed in pharmacies and drug stores, enabling women to avoid clinics altogether and access the drug in secrecy (Moland et al.,

\footnotetext{
S. Drabo $(\bowtie)$

Faculty of Medicine, Institute of Health and Society, University of Oslo, Oslo, Norway

e-mail: seydou.drabo@medisin.uio.no
} 
2018). This chapter shows how the uses of misoprostol to induce abortion depend less on the formal policies designed to regulate its use than on women's 'informal' use of the drug.

I analyse how misoprostol circulates outside Ouagadougou's formal healthcare system as a form of 'pharmaceutical diversion'. Ann Lovell defines pharmaceutical diversion as a process that connects formal healthcare providers and pharmacists with networks of individuals who 'diffuse the product and knowledge about it' beyond the clinic (Lovell, 2006, p.156). Thus, the chapter focuses on the microlevel of the everyday practices of individuals who seek to acquire, circulate and use diverted pharmaceuticals outside their formal regulated circuits, uses and applications. Similarly, women's uses of misoprostol can be conceptualized as what Childerhose and MacDonald (2013) call ‘domestication' - how consumers create new uses for biomedical goods, including drugs and devices that were never intended by manufacturers or regulators and are not overseen by professionals. The notion of domestication has particular relevance for how consumers bring biomedical goods into their homes for reasons of privacy and personal agency, in the sense of the ability to influence one's life by acting independently (Mortimer \& Shanahan, 2003). This research also reveals the critical role of intermediaries in the process of pharmaceutical diversion and domestication, which often creates inequalities in access to misoprostol, complicating the narrative of misoprostol as a therapeutic revolution in the prevention of unsafe abortion. This study reminds us that access to misoprostol varies across settings, and while relatively safer than clandestine forms of unsafe abortion, may also be marked by pre-existing social and economic constraints, vulnerabilities and inequities. Therefore, misoprostol is a drug that illustrates and confirms that drugs have a social life. The notion that medicines have a social life is well established in medical anthropology, referring to the fact that medicines are more than their chemical properties and effects in the body; the way they are produced, tested, circulated, used and made meaningful is always shaped by their social and cultural contexts (Van der Geest \& Whyte, 1989; Whyte et al., 2002).

\section{The Social, Legal and Policy Context of Misoprostol in Ouagadougou, Burkina Faso}

In 2008, it was estimated that one-third of all pregnancies among women aged 15-49 years in Burkina Faso were unintended. One-third of these unintended pregnancies ended in abortions (Bankole et al., 2014). The incidence of abortion for women of reproductive age in Burkina Faso was estimated at 25/1000 in 2012 (Bankole et al., 2014). That rate is comparable to the level observed in 2008 for the West Africa sub-region (28 per 1000 women aged 15-44 years) (ibid).

In Burkina Faso, induced abortion is socially stigmatized (Drabo, 2013) and legally restricted to cases of rape, incest, foetal malformation or endangerment to 
the woman's life. According to Burkina Faso's penal code, inducing abortion is punishable by up to 5 years of imprisonment and a fine and, in the case of a woman's death, up to 12 years for a person helping a woman to abort (La voix du Juriste, 2013). Due to the legal restrictions, most women seeking abortion resort to unsafe means to terminate their pregnancy, at significant risk to their health. It is estimated that half of women who induce their abortions alone experience complications, compared with about 2 in 10 women who go to healthcare providers performing illegal abortion (Bankole et al., 2014). The safety of abortion in this context depends on women's social and economic status and the differences between rural and urban areas in terms of cost, accessibility and safety (Bankole et al., 2014). Overall, safe abortion $^{1}$ methods are relatively inaccessible throughout Burkina Faso, especially for rural women (ibid). Ninety-seven percent of abortions performed in rural areas are unsafe and poor women in rural areas typically experience the most significant health risks. Seven in 10 women living in rural areas end their pregnancies themselves or use traditional practitioners who are perceived to be discreet.

The government response to unsafe abortion has been limited to implementing a Post-Abortion Care (PAC) policy to treat complications (Ouattara \& Storeng, 2014; Storeng \& Ouattara, 2014). A range of technological options, including emergency contraception, vacuum aspiration and medical abortion, are used to treat incomplete abortion and prevent unwanted pregnancy in Burkina Faso. Manual vacuum aspiration (MVA) and misoprostol were introduced in the care policy in 1998 and 2014, respectively. In urban areas, private or clinic-based doctors or other healthcare providers, such as midwives and auxiliary midwives, often carry out abortions illegally. Though more costly than those offered by traditional providers, these procedures, including MVA or misoprostol, are considered relatively safe compared to other methods such as the insertion of sticks or sharp objects into the vagina, the consumption or vaginal application of kola, abortifacients like herbal tea, potions and high doses of drugs like anti-malarials, or bleach (Bankole et al., 2014).

\section{Field Site and Methods}

My fieldwork focused on Ouagadougou, a city of 2.7 million (CWF, 2018), which is also Burkina Faso's capital and its administrative and economic centre. In Ouagadougou, women can access abortion care in the public sector only in the circumstances stipulated by law (incest, rape, foetal malformation, health of the mother). However, PAC services are offered in secondary and tertiary healthcare facilities, some primary healthcare facilities in the public sector and in private-care

\footnotetext{
${ }^{1}$ WHO classifies abortion as safe if it takes place using a safe method and is done by an appropriately trained provider. Less-safe abortions include those done by a trained provider but using an outdated method, and self-induced abortions using a relatively safe method (e.g., misoprostol); least-safe abortions are those done by an untrained person (a provider or the woman herself) using a dangerous method. Both 'less' and 'least' safe abortions are considered unsafe.
} 
facilities (Bodart et al., 2001). Misoprostol can be purchased to treat incomplete abortion and manage post-partum haemorrhage in the city's hundreds of pharmacies (Ministry of Health of Burkina Faso, 2014). Misoprostol also circulates outside the official framework in Ouagadougou, and it is often referred to locally as the 'abortion drug'.

Building on previous experience studying maternal mortality and PAC in Burkina Faso's health sector (Drabo, 2013; Storeng et al., 2013), two periods of ethnographic fieldwork were undertaken between 2015 and 2017 in the city of Ouagadougou. The fieldwork was conducted in the framework of my $\mathrm{PhD}$ research focused on the use of contraceptives and abortion drugs. During the first period (October to December 2015), I focused on healthcare professionals' use of misoprostol in nine health facilities, including two University Hospital Centres, four primary healthcare centres, one private medical centre and two private primary care centres. I conducted interviews or had informal discussions with 22 healthcare workers, including gynaecologists, midwives and auxiliary midwives working in maternity care units.

In the second period of fieldwork (March 2016 and February 2017), I focused on women's perspectives and experiences in seeking out an abortion, including medical abortion using misoprostol. I conducted participant observation in streets and market places, interacting regularly with various women and drug vendors. I observed pubs and the streets of Kwame Nkrumah, a main thoroughfare with many hotels, restaurants, pubs frequented by men and women who work as waitresses or sex workers, often referred to collectively as 'les filles de nuits' (girls of the night). These observations allowed me to start conversations around the issue of abortion and to negotiate in-depth interviews with some of the women, who, because of their work, are at risk of unintended pregnancy, abortion and their consequences (Drabo, 2019; Weldegebreal et al., 2015).

To understand the context of drug sales and the interactions between drug sellers and consumers, I conducted observations and informal discussions with street drug vendors by spending time with them in their market place. During events like movie festivals (FESPACO), the public authorities officially establish a merchant street where traders come to expose their products. Drug vendors participate in these activities by showing and selling their products for 1 week. I stayed in the store of one of the drug vendors who was selling non-western contraceptive methods and other drugs purchased by women. The long hours spent waiting there (3-6 h) gave me the opportunity to have discussions with both the drug vendor and some of his clients (see also Drabo, 2019).

In addition to participant observation, I conducted in-depth interviews with 46 women (in the context of my broader $\mathrm{PhD}$ research project) about their reproductive trajectories, perceptions and practices of contraceptive methods and abortion drugs and the decision-making processes and networks involved in the procurement of misoprostol. Healthcare workers assisted me in identifying women who had sought family planning and PAC and were willing to participate. I used my social networks to identify other participants from the general population. This strategy consisted of asking women who were closer to me (neighbours, former classmates and friends) and who agreed to participate in the study. Subsequently, I relied on these women to access other women (friends of friends) who were also willing to participate in the 
study. Of the 46 women I interviewed, 16 reported that they had undergone induced abortions in the past. These 16 interviews form the basis of the analysis in this paper. Among this group, nine were single women, four were cohabiting with a man, two were married and one was widowed. Seven of these women were working as servers in a pub, three were students, three were petty traders, one was a maid, one a housewife and one a public servant. Five of the women in this group had had more than one abortion. Together, these sixteen women had 23 abortions between 2010 and 2017. Ten of them reported using misoprostol to terminate one or more pregnancy. The other methods women used to terminate their pregnancy included MVA, potassium permanganate, Chinese pills and a recipe made with a plant (see also Drabo, 2019).

\section{Data Analysis and Ethical Issues}

I conducted interviews in French, Mooré or Dioula depending on participants' preferences (I speak these three languages fluently). Most interviews were tape-recorded (with the exception of three people who were more comfortable with note-taking) and transcribed verbatim. Interviews lasted between $20 \mathrm{~min}$ and $1 \mathrm{~h}$ and $30 \mathrm{~min}$. A research assistant transcribed the interviews and those recorded in Mooré or Dioula were translated into French. I did the final editing, checking all the transcripts to ensure accurate transcription and translation. I identified recurrent themes from interview transcripts and observational notes and analysed the texts based on the research question, which was focused on the use of misoprostol.

Quotes used in this chapter to illustrate the findings have been translated from French to English. I obtained ethical approval for the study from the Ethical Committee of Burkina Faso and the Norwegian Centre for Research Data. Informed consent forms were read aloud to the research participants, who provided verbal consent; verbal consent was also the most suitable because of the topic's sensitivity for healthcare providers, drug vendors and women. In addition to receiving informed consent, I assured my participants of my good intentions. For example, I made women understand 'my goal is not to judge but to understand'. This attitude allowed me to establish a climate of trust with participants to make them feel comfortable talking about their reproductive life experiences. I told all participants they could withdraw from the study at any time or choose not to participate in the study. The names of participants cited in the quotes are pseudonyms (see also Drabo, 2019).

\section{How Health Providers and Drug Vendors Circumvent the Regulation of Misoprostol}

There are mechanisms in place in health facilities to prevent misoprostol from being used outside the legal framework for its uses. Interviews with healthcare providers indicate only gynaecologists are authorized to prescribe misoprostol. In the medical 
centre and hospital, midwives are supposed to use it only under the supervision of a gynaecologist in the treatment of incomplete abortion and in the management of post-partum haemorrhage. In primary healthcare centres, only specially trained midwives are allowed to prescribe misoprostol without the advice of a doctor, and only for PAC. In practice, however, auxiliary midwives often prescribe and use it under the guidance of a midwife. Thus, gynaecologists, midwives and auxiliary midwives are involved in the management of misoprostol depending on the circumstances of care delivery. Furthermore, pharmacists and drug vendors explained that they are required by the Ministry of Health to write down the name of the health facility purchasing the drug, the date and the quantity of the product being purchased, as well as the name and the telephone number of the prescriber and the buyer. These restrictions are intended to avoid misoprostol being re-directed for induced abortion.

In addition to official regulations, health workers involved in the management of the drug in PAC take extra precautions to prevent patients from accessing misoprostol and using it to induce abortion. For example, some healthcare providers confiscate the remaining misoprostol tablets after PAC. A midwife in a district hospital explained: 'We tell them, for example, after prescribing that we cannot leave them with the rest of the product because they can be used to cause an abortion'. Despite regulations that aim to restrict the use of misoprostol to induce abortion, social and institutional factors enable its availability in the health system and individuals' access to it. First, misoprostol has been on the list of essential medicines for clinical use since 2014. Second, there are international and national NGOs working within the field of reproductive health who make misoprostol available in their private clinics and in some public health facilities claiming that they need it for PAC. Task shifting in care delivery allows midwives or auxiliary midwives to perform some of the therapeutic acts that are, on paper, restricted to gynaecologists. As a consequence, most of the healthcare providers working in maternity care units are able to acquire misoprostol and may use it to induce abortions. As a midwife working at the hospital explained: 'We used it for PAC, but there are people who use it to do abortions too. It happens, we have colleagues who do it and I will not give a name'.

In pubs, I observed that some sex workers and servers act as intermediaries between health workers providing abortion services clandestinely and women seeking abortion. Such links are sometimes established during sex workers' health visits and are mutually beneficial in providing sex workers with access to abortions and health workers' access to more clients in need of abortion services. For example, during one of my visits to a pub in Ouagadougou, I met Severine, a 20-year-old woman, who worked as server in the pub and also as a sex worker on the side. Severine told me that a male friend of hers who is a nurse gave her misoprostol tablets for free when she had an unwanted pregnancy and encouraged her to bring other girls who would need abortions to him.

The permissiveness of the drug distribution system in Burkina Faso, which allows individuals to access drugs without showing a prescription, generates conditions that permit illegal abortion (Ouedraogo, 2015). Like many other drugs in lowresource settings, misoprostol circulates as a commodity that can be sold and 
purchased informally (Van der Geest \& Whyte, 1989). Drug vendors play an important role in the illicit distribution of misoprostol, for example, by circumventing the rule to report information about the prescriber and the buyer of misoprostol. A drug vendor in a private pharmacy stated that he sometimes registers fake information in the drug sales record:

Often it is necessary to have a little imagination: you need the name of a recognized district hospital, it is very easy to write in the notebook. You put a doctor's name that we will never be checked and you write the product and the name of a fake buyer with wrong mobile number and the product is sold.

The same drug vendor explained that circumventing regulations is relatively straightforward; in 21 years of service, he has never been visited by an inspector. Social ties between drug vendors in pharmacies and healthcare workers can also facilitate women's access to misoprostol without a prescription. For example, one healthcare provider who admitted that he offers abortion services at his house explained how he procures misoprostol: 'As I am a health professional, I go with prescriptions to buy. I also know a lot of pharmacists who help me sometimes'.

These examples show the critical importance of intermediaries (health workers, drug sellers, sex workers, friends, etc.) in misoprostol access, though not all women depend on intermediaries to access misoprostol. Some women access misoprostol directly by going to a pharmacy; however, this requires tact and a certain ability to negotiate directly with drug vendors, as well as strong social networks or what Ouedraogo terms an 'abortion managing group' (Ouedraogo, 2015): all the individuals mobilized and involved in the abortion process (seeking out information, individuals, places or products that can assist in providing moral and financial support). In Ouagadougou, drug vendors in pharmacies, health workers and sex workers are among the actors involved in the networks that enable women to access misoprostol. These networks are often characterized by interactions that disappear once misoprostol is accessed. Later on, people involved in the process can contact each other again if the need for an abortion is expressed.

By ignoring the official requirement for a prescription and selling it off-label, drug vendors and health workers can be said to domesticate misoprostol. This domestication involves the diversion of misoprostol for illegal abortion, contrary to the official status assigned to it by Burkina Faso's health policies, and its sale as a commodity that has a negotiable price. These practices are encouraged by women's demands for clandestine abortions and give power to drug vendors and health workers, who can decide who can access the drug according to their rules and logics.

\section{Intermediaries' Motivations}

Some health workers helping a woman to get an abortion take the position that doing so is a matter of the woman's right to health, since doing so can help her avoid the serious social and health consequences of an unwanted pregnancy, whether the 
consequences of an unsafe abortion or the abandonment of children at birth. For example, one male midwife, who performs abortion illegally, said:

\footnotetext{
We have to help. They are women who come to give birth, they tell you vis-à-vis that the guy refused paternity. Sometimes they do not even know the person who is responsible for their pregnancy since they have dealt with two or three people. Some of them will tell you that they were raped. I tell myself that these people need help. There are also some other women who are ashamed because they have a little child. When all these women do not want pregnancy they take odd products to abort and then after they will face many complications. Those who decide to keep the pregnancy will give birth and throw away the baby.
}

Despite having declared their attitude to help people, individuals who sell misoprostol or practice abortion will do so following some conditions. For example, a drug vendor explained that he and his colleagues prefer requests from women who explain verbally that they need misoprostol, rather than someone who simply holds a piece of paper on which the name of the product is mentioned. In the latter case, drug vendors feel that they should not sell the product because of safety concerns: 'you will see some people who arrive with just a simple piece of paper where it is written misoprostol. You can feel he does not even know what kind of product he is buying. If you give it to them, they may misuse it. So, to avoid problems we refuse to sell'. As for health workers who practice abortion, like the one I met, he helps only people referred to him through his social network; the 'client' has to come through someone he already knows, otherwise she is rejected.

Although misoprostol circulates beyond the clinic and the control of health workers, accessing it is thus not a given and requires negotiation. While health workers and drug vendors may be motivated to provide misoprostol for women on altruistic grounds, others judge the women's need and ability to pay before setting a price or other terms of exchange. In short, buying misoprostol tablets is not just an economic transaction but also a complex process of networks and negotiation, which often involves vendors exerting power over the terms of access to the product.

\section{Pharmaceutical Diversion of Misoprostol by Women}

Pharmaceutical (drug) diversion refers to the transfer of any legally prescribed controlled substance from the individual for whom it was prescribed to another person for any illicit use (Berge et al., 2012; Lovell, 2006). By using this notion, I refer to the way misoprostol, which is meant to be used for official indications such as PAC and the treatment of post-partum haemorrhage, is rather used for acts such as illegal abortions. Through the channel of friends and relatives, drug vendors and healthcare workers, women are able to access misoprostol to induce abortion. Despite the fact that it allows for self-induced abortion, the involvement of abortion providers seems important because they appear as 'skilled' players regarding the use of the drug. Moreover, the involvement of abortion providers in some cases has changed women's access to illegal-induced abortion because it allows abortion providers to perform abortion discreetly (Drabo, 2019). As 23-year-old Awa explained: 
My boyfriend contacted a doctor who gave us an appointment in front of a guest house. My boyfriend paid for the room and then waited outside. I went inside with the doctor who put some white pill inside me...After that I did not see him again. When I arrived home, I started bleeding a bit and it came out.

This example shows how misoprostol enables clandestine abortion providers to work discreetly, by removing the procedure from the healthcare setting where providers may risk prosecution if complications occur. Thus, both women and abortion providers benefit from the discretion misoprostol allows.

In addition to meeting the need for discretion, misoprostol also changes the cost of illegal abortion services. Women report that abortion with misoprostol was relatively affordable, around 8000 XOF (1 USD approximatively equal 580 XOF), compared to abortion induced illegally by MVA, which can cost around 25,000 $\mathrm{XOF}$. Furthermore, the price of misoprostol varies depending on how the product is accessed. It is relatively cheaper when women procure it to have a self-induced abortion than when they pass through a health worker. In the latter case, it is the price of abortion that is fixed and not that of the drug. As one informant told me, 'The price of abortion varies between 25,000 XOF to 200,000 XOF. Last time I was dealing with a former minister. I asked him to pay 200,000 XOF. In addition, with the population it varies from $25,000 \mathrm{XOF}$ to $100,000 \mathrm{XOF}$.

The variation of the price of an abortion, which is fixed by the abortion provider based on individual financial resources, suggests that people getting involved in illegal activities like abortion (by asking for the support of abortion providers) could render them susceptible to extortion. Accounts of individuals involved in the provision of abortion services show that although some abortion providers claim to 'help' women, abortion services always come at a price. Misoprostol establishes what Fiske has called an 'instrumental relationship' (Fiske, 1992) between drug vendors, healthcare providers and women (with their supportive person), meaning a relationship characterized by mercantile interest between people involved in a social interaction. This gives rise to negotiation between those who need and those who distribute misoprostol in which the price of the product is adjusted according to the characteristics of the purchaser. For example, the price may be lower or easily negotiated if the purchaser knows the provider or is introduced to them through a friend. Some women I spoke with accessed misoprostol without paying anything because their acquaintances gave them the drug for free, such as 35-year-old Diane, whose partner of 17 years is the father of her two children. After she announced her third pregnancy, her partner asked her to have an abortion and threatened to leave her if she kept the pregnancy. Diane decided to contact one of her friends, a medical doctor, to get misoprostol, who gave it to her free of charge. As she explained:

When I had my problem, I got the product for free. A friend helped me to get it from another friend. He did not buy it either because they are both health professionals and they mutually support each other. The other could not refuse because he knows that one day he may also need help (not only abortion) from my friend.

In addition to receiving misoprostol free of charge from friends in the medical system, women described how they obtained misoprostol from female friends or 
relatives who had used it to self-induce abortion. These female friends or relatives gave the remaining pills from the packet they purchased as a gift. One woman confided that though she never had an abortion, her cousin gave her some misoprostol tablets in case she would need it one day. She interrupted the interview to go get the tablets and showed me a blister pack with six tablets missing.

As a gift, misoprostol reinforces the bonds of solidarity, friendship and kinship between women (Gregory, 1982), and means that one woman's abortion can allow that of another woman. Such informal exchanges highlight the agency of women and their role in 'domesticating' misoprostol (that is, how they create a use for the drug that was not intended by regulators) and disrupting the supply chain of misoprostol ordinarily controlled by healthcare workers and drug vendors. This concept of domestication (Childerhose \& MacDonald, 2013) emphasizes agency and resourcefulness in the adaptation of technology for one's own ends. However, this adaptation ability is not the case for all women who seek to access misoprostol though informal networks.

\section{When the Diversion of Misoprostol Reproduces Social Inequities}

Although women with strong social networks, including friends and relatives who know healthcare workers or drug sellers, may access misoprostol relatively easily and at little or no cost, other women struggle to obtain the drug. They struggle to find information about where to buy it and the right way to induce abortion. These difficulties in accessing misoprostol push some women to turn to private clinics recognized to provide abortion services at a higher price than they can afford, as highlighted in Francine's story.

Francine, a 23-year-old domestic maid, became pregnant with a 16-year-old boy and decided to terminate the pregnancy. After a week of unsuccessful research, she was finally able to find, through a friend, a private clinic that belongs to an NGO offering abortion services discreetly. Once in the clinic, she paid a consultation fee of 2000 XOF out of her monthly salary of 10,000 XOF. After group family planning counselling, each woman explained their problem to a health worker. Francine told me that she had invented a story in order to convince the health worker to offer her an abortion: 'I told her that the 'author of the pregnancy' (local term to describe the father) had fled and that I had no one to support me. I added that my mother is strict and would banish me from the family'.

After Francine's explanations, the health worker decided to help her. She gave her a piece of paper on which she wrote her name and telephone number and asked Francine to forward it to another health worker (working in the same clinic) who would understand the message. After reading the note, the health worker decided to proceed with the abortion, but first told Francine she needed to do an ultrasound to confirm the pregnancy and its gestation. At a cost of $7500 \mathrm{XOF}$, the ultrasound was 
unaffordable for Francine. She left the clinic and returned the following day after she found the necessary money with the support of her uncle (by pretending she was sick). The ultrasound confirmed that she was 2 months pregnant. After the ultrasound, the health worker asked her to do other tests, including serology test, blood type and hepatitis B, which cost 8500 XOF in total.

After the results of these examinations, the health worker gave her four pills, which she drew discreetly from her drawer. She instructed Francine to keep the pills under her tongue for $30 \mathrm{~min}$ before swallowing. Then she wrapped another eight tablets in paper and told her to swallow four tablets every $3 \mathrm{~h}$. These tablets cost 15,000 XOF. Francine had no complications after this abortion. As this case illustrates, while Francine's friend directed her to abortion services in a private clinic, even with misoprostol, the cost of the abortion was more than three times Francine's monthly salary.

The experience of Anna, a 30-year-old, exemplifies how accessing abortion means not only incurring unplanned expenses and having trouble accessing abortion services but also experiencing failed abortions, frequenting several different abortion providers and intimidation (Drabo, 2019).

Anna is employed as a hairdresser and earns between 15,000 XOF to 20,000 XOF a week, but supplements her meagre income through sex work. Anna calls her boyfriend a crook and stingy because he cheats people on the internet to get money, but refuses to support her financially when she is in need. She decided to terminate the pregnancy since she was concerned that her boyfriend would take the child to his home country. As she said: "I am not going to struggle to give birth to a child and they will come and take it from me one day". When Anna was one month pregnant, she asked a friend to escort her to a woman who she knew conducted abortions in her home. According to Anna, this abortion provider is not a healthcare worker but she learned how to conduct abortions after working with a healthcare worker.

However, when Anna and her friend arrived at the woman's home, she sent them away, stating that she did not perform abortions. Anna and her friend visited the woman several times over a period of eight days before she finally agreed to help them. She asked them to pay 20,000 XOF, before placing a white product (misoprostol) in Anna's vagina and explaining that once Anna reached home, the fetus would be expelled. Unfortunately, the pregnancy was still intact after a week. After this failed abortion attempt, Anna was afraid to go back to see the woman because their previous meetings were difficult. With the help of the same friend, she decided to go to a clinic known to practice clandestine abortions. Once she reached the clinic, the man who owned the clinic requested that she pay 2000 XOF for the examination. After the examination, he fixed the price of Anna's abortion at 50,000 XOF and gave her an appointment for the same afternoon. Anna did not have enough money but decided to go to the appointment anyways with the intention of negotiating a discount. Once in the clinic, a secretary in the clinic discreetly informed Anna that she knew a place where Anna could have an abortion for less. Anna accepted the offer and was directed to the home of another woman. However, when Anna reached the woman's home, the lady rejected Anna and threatened to call the police. Anna was not able to convince the woman to conduct the abortion until the clinic 
secretary escorted her. Finally, the woman agreed to perform Anna's abortion in her house using aspiration at a cost of 30,000 XOF.

Although Francine and Anna's experiences differ, they illustrate that, despite the influx of misoprostol, obtaining an abortion in Ouagadougou is a costly and often stressful process. The availability of misoprostol outside the formal healthcare system may not guarantee access nor a successful abortion for less well-resourced and connected women. In addition, given that illegal abortion often obeys the rule of "no one knows', in case of failure, women do not hold the abortion providers accountable. Instead, they go to official health facilities to get support for treatment if complications occur, or resort to another abortion provider, like in Anna's case.

Furthermore, intermediaries often exercise control over the process of diverting the drug into the hands of women; many women are vulnerable to exploitation by providers of the drug on whom they are dependent. Conversations with women revealed that some women who need to access misoprostol become victims of sexual harassment or abuse from abortion providers. Claudine, a 24-year-old student, explained her experience with one informal abortion provider:

This man, everybody knows him...He tried to date me and asked for my phone number but I refused. One day I asked for his help because one of my friends wanted to get rid of her pregnancy. He came home and placed the tablet inside...Then he showed us the remaining tablets and told me that my friend must have this last one to finish the abortion. However, that she was not going to get it until he received my telephone number. Since that time, he disturbs me.

In another case, Lisa, a 34-year-old restaurant owner, became friends with a 19-yearold student, who was a regular customer. The student confided in Lisa that she encountered trouble while seeking misoprostol for an abortion. As Lisa explained to me:

It would have been interesting for you to meet this girl... She suffered a lot because she told me she was pregnant and did not want her parents to know about it. However, she had no money to do the abortion. X [a known abortion provider] helped her to abort using a pill but on the condition of having sex with her... without a condom.

Some women reported that they chose to self-abort in order to avoid harassment, though doing so incurs the risk of inappropriate use of abortion drugs. For instance, Sali, a 21-year-old woman working in a pub, got misoprostol from a friend, who did not tell her how to use it. She took the entire tray at the same time (14 tablets) and she was later admitted to hospital due to dizziness and pelvic pain. Abortion service providers confirmed in interviews that although many women know about misoprostol and that it can be used to induce abortion, few women know the appropriate dosage. This shows how access to misoprostol does not necessarily guarantee a safe abortion.

\section{Discussion and Conclusion: Safe Access to Safe Abortion}

In this chapter, I have shown that understanding access to misoprostol for safe abortion requires going beyond the analysis of formal policies and institutions to study people's actual micro-practices. Despite a legal and regulatory framework that aims 
to restrict the use of misoprostol for induced abortion, some health workers and drug vendors in pharmacies successfully divert misoprostol for illegal abortions, and some women successfully domesticate it for use in their own homes. The availability of misoprostol outside the formal healthcare system seems to reduce the cost women pay for induced abortion, corroborating findings from other studies (Ngai et al., 2000; Leone et al., 2016; Singh et al., 2018; Moland et al., 2018). Even so, improved access to misoprostol does not necessarily equate with safe access to safe abortion (Drabo, 2019).

In fact, much like de Zordo's findings from Brazil (De Zordo, 2016), my study suggests that there is an inequality of access to misoprostol; some women have bargaining power because of their social status and can easily access misoprostol, whereas others cannot. For some women, the route to access is through a network of drug vendors, health workers and sex workers, while others are able to get it directly from private pharmacies or NGO clinics. My findings resonate with a recent study from Ouagadougou showing that misoprostol is used predominantly among women who have attended secondary and post-secondary education and women who have high socioeconomic status (Baxerres et al., 2018).

My findings contribute in several distinct ways to the literature on the topic. First, inequities in access to healthcare innovations are often pictured in terms of dichotomies between urban-rural residence and poverty status (Singh et al., 2018). Meanwhile, my analysis highlights inequities in access to abortion or abortion drugs between people within the same geographical area, as is the case in Ouagadougou. Second, though my study affirms the importance of social networks or 'abortion management groups' in accessing abortion within legally restricted settings like Burkina Faso (Ouedraogo, 2015), the notion of an abortion management group does not fully capture the fact that the management of abortion often occurs through loose, occasional, networks rather than cohesive bounded groups, as I have shown. By circulating misoprostol in their close social networks as a gift, however, even poor women may break the access networks often controlled by health workers and drug vendors and in some instances domesticate the drug for their use at times and places they decide. Finally, my analysis challenges predominant technical definitions of 'safe abortion' that focus on the outcome of the abortion procedure and the professional competence of the operating agent (World Health Organization, 2015). While the diversion and domestication of misoprostol may increase women's access to safe abortion and make it possible to relocate abortion practices to guesthouses and other places, the process is not always conducive to safety. In some cases, the diversion of misoprostol creates conditions that allow the unpleasant treatment or even sexual abuse of vulnerable women. Thus, for some women, the route to accessing a safer abortion, medically speaking, can be unsafe. Access to misoprostol therefore does not necessarily guarantee a safe abortion.

By apprehending misoprostol in its dynamic uses, this study shows how global policies on drugs such as misoprostol can mask social inequalities and power relations around its uses. Actors advocating for safe abortion and policy makers can learn from this Burkinabe example, which shows that a drug like misoprostol, regardless of its properties and its therapeutic effectiveness, cannot alone ensure safe abortion. Indeed, for misoprostol to solve the problem of unsafe abortion 
globally, women need to be able to access it equitably and safely. However, as long as its use occurs within a legally restrictive context like that of Burkina Faso, the actors and networks that emerge to fill the access gap will not treat all women equally or well, and safe access to safe abortion remains somewhat elusive.

\section{References}

Bankole, A., Hussain, R., Sedgh, G., Rossier, C., Kaboré, I., \& Guiella, G. (2014). Unintended pregnancy and induced abortion in Burkina Faso: Causes and consequences. Guttmacher Institute.

Baxerres, C., Boko, I., Konkobo, A., Ouattara, F., \& Guillaume, A. (2018). Abortion in two francophone African countries: A study of whether women have begun to use misoprostol in Benin and Burkina Faso. Contraception, 97(2), 130-136. https://doi.org/10.1016/j. contraception.2017.10.011

Berge, K. H., Dillon, K. R., Sikkink, K. M., Taylor, T. K., \& Lanier, W. L. (2012). Diversion of drugs within health care facilities, a multiple-victim crime: Patterns of diversion, scope, consequences, detection, and prevention. Mayo Clinic Proceedings, 87(7), 674-682. https://doi. org/10.1016/j.mayocp.2012.03.013

Bodart, C., Servais, G., Mohamed, Y. L., \& Schmidt-Ehry, B. (2001). The influence of health sector reform and external assistance in Burkina Faso. Health Policy and Planning, 16(1), 74-86. https://doi.org/10.1093/heapol/16.1.74

Childerhose, J. E., \& MacDonald, M. E. (2013). Health consumption as work: The home pregnancy test as a domesticated health tool. Social Science \& Medicine, 86, 1-8. https://doi. org/10.1016/j.socscimed.2013.02.035

De Zordo, S. (2016). The biomedicalisation of illegal abortion: The double life of misoprostol in Brazil. História, Ciências, Saúde-Manguinhos, 23(1), 19-36.

Drabo, S. (2013). Access to Post Abortion Care (PAC) in Burkina Faso: An ethnographic study. Master's Thesis. University of Oslo.

Drabo, S. (2019). A pill in the lifeworld of women in Burkina Faso: Can misoprostol reframe the meaning of abortion. International Journal of Environmental Research and Public Health, 16(22), 4425. https://doi.org/10.3390/ijerph16224425

CIA World Factbook. (2018). Burkina Faso demographics profile 2018. https://www.indexmundi. com/burkina_faso/demographics_profile.html. Accessed 28 Apr 2018.

Fernandez, M. M., Coeytaux, F., de León, R. G. P., \& Harrison, D. L. (2009). Assessing the global availability of misoprostol. International Journal of Gynecology \& Obstetrics, 105(2), 180-186. https://doi.org/10.1016/j.ijgo.2008.12.016

Fiske, A. P. (1992). The four elementary forms of sociality: Framework for a unified theory of social relations. Psychological Review, 99(4), 689.

Gregory, C. A. (1982). Gifts and commodities (Vol. 2). Academic.

Hofmeyr, G. J. (2012). Obstetric use of misoprostol: Innovations, evidence, controversy and global health perspectives. University of the Witwatersrand, Faculty of Health Sciences. Thesis (D.Sc.).

La voix du Juriste. (2013). Code penal de 1996.

Leone, T., Coast, E., Parmar, D., \& Vwalika, B. (2016). The individual level cost of pregnancy termination in Zambia: A comparison of safe and unsafe abortion. Health Policy and Planning, 31(7), 825-833. https://doi.org/10.1093/heapol/czv138

Lovell, A. M. (2006). Addiction markets: The case of high-dose buprenorphine in France. In Petryna, A., Lakoff, A., Kleinman, A. (Eds.), Global pharmaceuticals: Ethics, markets, practices (pp. 136-170). Duke University Press. 
Ministry of Health of Burkina Faso. (2014). Liste national des medicaments et consommables medicaux essentiels. https://www.medbox.org/pdf/5e148832db60a2044c2d5cdc. Accessed 9 Oct 2021.

Moland, K. M., Haukanes, H., Tadele, G., \& Blystad, A. (2018). The paradox of access-abortion law, policy and misoprostol. Tidsskrift for den Norske laegeforening: tidsskrift for praktisk medicin, ny raekke, 137(2), 1-6. https://doi.org/10.4045/tidsskr.17.0809

Mortimer, J. T., \& Shanahan, M. J. (Eds.). (2003). Handbook of the life course. Plenum.

Ngai, S. W., Tang, O. S., Chan, Y. M., \& Ho, P. C. (2000). Vaginal misoprostol alone for medical abortion up to 9 weeks of gestation: Efficacy and acceptability. Human Reproduction, 15(5), 1159-1162. https://doi.org/10.1093/humrep/15.5.1159

Ouattara, F., \& Storeng, K. T. (2014). L'avortement volontaire au Burkina Faso: Quand les réponses techniques permettent d'éviter de traiter un problème social. Autrepart, 70(2), 109-123.

Ouedraogo, R. (2015). "L'avortement, ses pratiques et ses soins». une anthropologie des jeunes au prisme des normes sociales et des politiques publiques de santé au Burkina Faso. Université de Bordeaux.

Potts, M. (2006). Misoprostol in practice. In Plenary lecture at the international conference on the prevention of post Partum Hemorrhage. Goa, India.

Singh, S., Remez, L., Sedgh, G., Kwok, L., \& Onda, T. (2018). Abortion worldwide 2017: Uneven Progress and unequal access. Guttmacher Institute.

Storeng, K. T., \& Ouattara, F. (2014). The politics of unsafe abortion in Burkina Faso: The interface of local norms and global public health practice. Global Public Health, 9(8), 946-959. http://dx.doi.org/10.1080/17441692.2014.937828

Storeng, K. T., Drabo, S., \& Filippi, V. (2013). Too poor to live? A case study of vulnerability and maternal mortality in Burkina Faso. Global Health Promotion, 20(1_suppl), 33-38. https://doi. org/10.1177/1757975912462420

Van der Geest, S., \& Whyte, S. R. (1989). The charm of medicines: Metaphors and metonyms. Medical Anthropology Quarterly, 3(4), 345-367.

Weldegebreal, R., Melaku, Y. A., Alemayehu, M., \& Gebrehiwot, T. G. (2015). Unintended pregnancy among female sex workers in Mekelle city, northern Ethiopia: A cross-sectional study. BMC Public Health, 15(1), 40. https://doi.org/10.1186/s12889-015-1366-5

Whyte, S. R., Van der Geest, S., \& Hardon, A. (2002). Social lives of medicines. Cambridge University Press.

Winikoff, B., \& Sheldon, W. (2012). Use of medicines changing the face of abortion. International Perspectives on Sexual and Reproductive Health, 38(3), 164-166.

World Health Organization. (2006). The selection and use of essential medicines: Report of the WHO expert committee, 2005 (including the 14th model list of essential medicines) (Vol. 933).

World Health Organization. (2015). Health worker roles in providing safe abortion care and post abortion contraception. https://www.ncbi.nlm.nih.gov/books/NBK316326/. Accessed 9 Oct 2021.

Open Access This chapter is licensed under the terms of the Creative Commons Attribution 4.0 International License (http://creativecommons.org/licenses/by/4.0/), which permits use, sharing, adaptation, distribution and reproduction in any medium or format, as long as you give appropriate credit to the original author(s) and the source, provide a link to the Creative Commons license and indicate if changes were made.

The images or other third party material in this chapter are included in the chapter's Creative Commons license, unless indicated otherwise in a credit line to the material. If material is not included in the chapter's Creative Commons license and your intended use is not permitted by statutory regulation or exceeds the permitted use, you will need to obtain permission directly from the copyright holder.

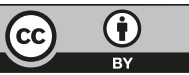

